\title{
The incidence and severity of hangover the morning after moderate alcohol intoxication
}

\author{
Jonathan Howland', Damaris J. Rohsenow², Donald Allensworth-Davies ${ }^{3}$, Jacey Greece', \\ Alissa Almeida', Sara J. Minsky', J. Todd Arnedt ${ }^{4}$ \& John Hermos' \\ Youth Alcohol Prevention Center, Boston University School of Public Health, Boston, MA, USA,' Center for Alcohol and Addiction Studies, Brown University, \\ Providence, RI, USA, ${ }^{2}$ Data Coordinating Center, Boston University School of Public Health, Boston, MA, USA ${ }^{3}$ and University of Michigan Medical School, Ann \\ Arbor, MI, USA ${ }^{4}$
}

\section{ABSTRACT}

Aims To determine the incidence and covariates of hangover following a night of moderate alcohol consumption at a targeted breath alcohol level. Design Data were combined from three randomized cross-over trials investigating the effects of heavy drinking on next-day performance. A total of 172 participants received either alcoholic beverage (mean $=0.115 \mathrm{~g} \%$ breath alcohol concentration) or placebo on one night and the other beverage a week later. The next day, participants completed a hangover scale. Participants Participants were 54 professional merchant mariners attending a recertification course at Kalmar Maritime Academy (Kalmar, Sweden) and 118 university students or recent graduates recruited from greater Boston. Setting One trial was conducted at Kalmar Maritime Academy (Sweden); the other two were conducted at the General Clinical Research Center at Boston Medical Center. Measurements A nine-item scale assessed hangover. Findings Hangover was reported by $76 \%$ of participants. Neither alcoholic beverage type nor participant characteristics was associated with incidence of hangover. Conclusions Our findings on the propensity of hangover suggest that $25-30 \%$ of drinkers may be resistant to hangover.

Keywords Alcohol, congeners, family history of alcohol problems, hangover resistance, hangover, heavy drinking, moderate alcohol intoxication.

Correspondence to: Jonathan Howland, Department of Social and Behavioral Sciences, Boston University School of Public Health, 715 Albany Street, Boston, MA 02118, USA. E-mail: jhowl@bu.edu

Submitted 20 April 2007; initial review completed 31 August 2007; final version accepted 27 November 2007

\section{INTRODUCTION}

Hangover refers to the cluster of symptoms following heavy drinking, occurring shortly after much or all of the alcohol has metabolized. Many plausible causes for alcohol-induced hangovers have been proposed, but studies to date have not provided sufficient data to confirm either a unitary or multi-factorial hypotheses. Proposed mechanisms broadly include metabolic, fluidbalance, hormonal and nutritional disturbances, toxicities resulting from alcohol and congener metabolism, sleep disruptions and personal susceptibilities relating to drinking behaviors, gender and genetics. These hypotheses have been arrayed elsewhere [1-3]. It is important to understand the factors associated with variation in hangover susceptibility, because susceptibility may affect drinking practices.
There is limited information on the incidence of hangover, although some survey data are available for specific populations. Frone reported that $7 \%$ (equal to about 11595377 workers) of a probability sample of US workers experienced hangover at work during the previous year [4]. One survey of college students found that $25 \%$ reported hangover during the previous week [5]. Harburg et al. found that $23 \%$ of surveyed drinkers reported not experiencing hangover the last time they were intoxicated [6]. In a study of patients admitted for alcohol detoxification, 23\% reported never having had a hangover [7]. Although the 2001-02 National Epidemiologic Survey of Alcohol Related Conditions (NESARC) did not ask specifically about hangover, it did ask a sample of 43093 adults about nine "bad aftereffects that people may have when the effects of alcohol are wearing off'. Using the NESARC data, we calculated that $21 \%$ of 
drinkers (22\% of males and $21 \%$ of females) experienced at least one of these after effects within the previous year. However, in surveys the incidence of hangover cannot be determined for specific levels of alcohol exposure. Furthermore, surveys may be subject to recall and attribution biases.

Experimental studies allow determination of the incidence and severity of hangover following specific levels of intoxication, controlling other factors that could affect symptoms. Although a number of experimental studies report on the next-day effects of alcohol consumption on neurocognitive performance [8-11] or occupational performance [12-24], few provide details on the incidence of hangover after controlled alcohol administration.

An exception is a study by Chapman [3], who administered beverage alcohol to 91 (50 males, 41 females) young adult drinkers. Ten received $1.0 \mathrm{ml} / \mathrm{kg}$ of alcohol [mean peak breath alcohol concentration (BrAC): $0.066 \mathrm{~g} \%$ ]; 10 received $1.25 \mathrm{ml} / \mathrm{kg}$ (mean peak BrAC: $0.11 \mathrm{~g} \%$ ); 60 received $1.5 \mathrm{ml} / \mathrm{kg}$ (mean peak BrAC: $0.13 \mathrm{~g} \%$ ); and another 11 received $1.75 \mathrm{ml} / \mathrm{kg}$ (mean peak BrAC: $0.14 \mathrm{~g} \%$ ). Overall, $68 \%$ of participants reported hangover the next morning, with incidence correlating roughly with the quantity of alcohol administered. However, because three of the dose levels had only 10 or 11 participants, the figures are unstable. Also, Chapman's data show that peak BrAC is a better predictor than $\mathrm{g} / \mathrm{kg}$ dose of alcohol in determining hangover severity. Thus, studies of hangover incidence following specific BrACs are needed.

Because susceptibility to hangover can vary across individuals who have consumed equivalent amounts of alcohol, it would be useful to know what factors covary with hangover incidence and intensity.

The congener content (e.g. acetone, acetaldehyde, methanol) of alcoholic beverages may affect hangover incidence or intensity. Bourbon has 37 times the amount of congeners as vodka [25] and in some studies [26], but not others [25], intoxication with bourbon was more impairing than with vodka. Smith \& Barnes [27] found no differences in the incidence of hangover by alcoholic beverage preferences (wine, beer, liquor) when controlling for levels of consumption, but congener content varies widely within each of these beverage classes [28], so these comparisons are unreliable. In Chapman's study, $78 \%$ of those receiving bourbon versus $59 \%$ of those receiving vodka reported hangover, although this difference was not significant [3]. Another study reported hangover effects increasing with congener content [29].

Family history of drinking problems (FHx) might affect hangover incidence, as this may reflect biological differences in response to alcohol. Generally survey studies have found that FHx is associated with propen- sity for hangover, controlling for reported drinking practices [30-34], although Earleywine [35] and Richardson [36] found no such association in samples of college students.

Drinking practice might affect hangover incidence due to tolerance. Survey studies have yielded mixed results [7,27,37]. Smith \& Barnes [27] and Kauhanen et al. [37] found that heavier drinkers reported more frequent hangovers than lighter drinkers. In contrast, Pristach et al. [7] found that $50 \%$ of a group of alcoholics had not had a hangover in the previous year.

Gender might be another predictor of hangover incidence. Neither Chapman's [3] experimental study nor the survey study by Harburg et al. found differences in hangover incidence by gender [6]. Smith \& Barnes found that more men than women drinkers experienced hangover, but this could be due to differences in amounts consumed [27].

For the present study, we combined data from three randomized studies we conducted on the effects of moderate/heavy alcohol administration (mean $=0.11 \mathrm{~g} \% \mathrm{BrAC})$ on next-day neurocognitive and/or simulated occupational performance. In studies 1 and 2, participants received high-alcohol beer; in study 3 participants received (randomly) either bourbon or vodka. This allowed us to investigate congener effects by comparing bourbon to vodka (422 versus $11 \mathrm{mg} / 100 \mathrm{ml}$ total congeners) [25]. The congener content of highalcohol beer is not available, although regular-strength beers average 6.8 times as many congeners as 80 proof vodka [28]; thus, high-alcohol beer should have intermediate congener content.

Participants rated their hangover on a scale ranging from 'no hangover' to 'incapacitating hangover'. Use of the word 'hangover' in the survey instrument involves attribution to residual alcohol effects [33]. None the less, in our studies this item had the highest item-total correlation and the highest validity [38]. We also asked participants to rate, without attribution, several symptoms associated with hangover [38], but which could occur in the absence of drinking. The same administration procedures targeted BrAC levels, and participant eligibility criteria were used. Thus, we can compare alcoholic beverages, at comparable mean BrACs, with respect to the incidence of hangover and specific hangover symptoms. We can also investigate the association of hangover to participant characteristics [e.g. age, gender, average daily volume of alcohol (ADV), FHx]. Our aims were: (i) to investigate the incidence of any hangover and of severity of hangover the day after a specific narrow BrAC range among non-alcoholic drinkers; and (ii) to investigate congener content (bourbon versus vodka) and participant differences as determinants of variability in hangover incidence. 
Table 1 Participant characteristics.

\begin{tabular}{|c|c|c|c|c|}
\hline & \multicolumn{4}{|l|}{ Beverage studied } \\
\hline & $\begin{array}{l}7.2 \% \text { ABV beer } \\
(n=93)\end{array}$ & $\begin{array}{l}\text { bourbon } \\
(n=36)\end{array}$ & $\begin{array}{l}\text { vodka } \\
(n=43)\end{array}$ & $\begin{array}{l}\text { Total } \\
(n=172)\end{array}$ \\
\hline Male** & $72(77.4 \%)$ & $15(41.7 \%)$ & $13(30.2 \%)$ & $100(58.1 \%)$ \\
\hline \multicolumn{5}{|l|}{ Age } \\
\hline Mean \pm SD & $28.9 \pm 8.9$ & $24.2 \pm 2.6$ & $24.2 \pm 2.6$ & $26.7 \pm 7.2$ \\
\hline Range & $21-57$ & $21-31$ & $21-31$ & $21-57$ \\
\hline FHx positive & $26(28.3 \%)$ & $8(22.2 \%)$ & $11(25.6 \%)$ & $45(26.2 \%)$ \\
\hline \multicolumn{5}{|l|}{ Weight (lb)* } \\
\hline Mean \pm SD & $174.5 \pm 42.0$ & $153.3 \pm 23.8$ & $153.2 \pm 28.5$ & $164.7 \pm 37.1$ \\
\hline Range & $90-369$ & $111-235$ & $103-234$ & $90-369$ \\
\hline Smokers & $17(18.3 \%)$ & $3(8.3 \%)$ & $3(7.0 \%)$ & $23(13.4 \%)$ \\
\hline
\end{tabular}

ABV: alcohol by volume; FHx: family history; SD: standard deviation. ${ }^{*} P<0.001$; ${ }^{*} P<0.0001$.

\section{METHODS}

\section{Participants}

Participants were 54 professional merchant mariners attending a course at Kalmar Maritime Academy (Kalmar, Sweden) (study 1) and 118 university students recruited in greater Boston (studies 2 and 3). Participants had to be at least 21 years of age and meet the following criteria: (i) no serious drinking problems (score $<5$ on the Short Michigan Alcohol Screening Test (SMAST) [39] and no history of treatment for alcohol problems; (ii) more than five drinks on a single occasion (more than four if female) at least once 30 days prior to screening; (iii) no health problems or current medication use contraindicated for alcohol; (iv) fluent English; (v) recently graduated from, or currently attending, an institution of higher learning (studies 2 and 3); and (vi) negative pregnancy test and not nursing, if female. Females were not screened for menstrual cycle [40-42]. Before beverage administration, participants who reported consuming alcohol, caffeine, prescription or over-the-counter drugs within the previous 24 hours, or food or beverage within the previous 3 hours, were rescheduled; those presenting with a positive BrAC were excluded from further participation; see Table 1 for participant characteristics. Under alcohol condition, the peak mean BrAC was $0.11 \mathrm{~g} \%$ [standard deviation $(\mathrm{SD})=0.01$; range $=0.09$ $0.15 \mathrm{~g} \%$ ]. Thirty-three per cent (57) of respondents had BrAC between 0.09 and $0.104 ; 50.6 \%$ (87) between 0.105 and $0.124 ; 8.7 \%$ (15) between 0.125 and 0.134 ; and $7.6 \%$ (13) between 0.135 and 0.155 . There were significant differences across beverage types for sex $(P<0.0001)$, but not for age, FHx, ADV or peak BrAC.

\section{Study design}

The three studies used a double-blinded, within-subjects, cross-over design (i.e. each participant served as his/her own control) wherein all the subjects received two beverage conditions (alcohol and placebo) in counter-balanced order. Participants took part in the studies over 4 days ( 2 consecutive days followed a week later by 2 consecutive days).

\section{Procedures}

On the first evening, participants were randomized within gender to receive either alcoholic beverage or an equivalent amount of placebo; on the second evening they received the other beverage. They were told that they had a $50 \%$ chance of receiving alcohol the on first night and would receive the other beverage on the other night.

\section{Beverage administration procedures}

Alcoholic beverage administration targeted $0.10 \mathrm{~g} \%$ $\operatorname{BrAC}(1.2 \mathrm{~g} / \mathrm{kg}$ body weight for men and $1.1 \mathrm{~g} / \mathrm{kg}$ for women [43]). If participants randomized to alcohol did not reach $0.10 \mathrm{~g} \% \mathrm{BrAC}$ after their final scheduled drink, the ratio of actual to target $\mathrm{BrAC}$ was used to determine an additional amount of beverage administered. To maintain blinding, some placebo participants also received extra beverage.

In studies 1 and 2 the beverage alcohol was beer (7.3\% alcohol by weight) (Elephant Beer ${ }^{\circledR}$; Carlsberg A/S, 100 Ny Carlsberg, DK-1760, Copenhagen, Denmark) and the placebo was Clausthaler ${ }^{\circledR}$ non-alcoholic beer (Radeberger Gruppe, Darmastaedter Landstrasse 185, Frankfurt, Germany). High-alcohol beer was used to reduce the volume. In study 3 , the alcoholic beverages were bourbon (101 proof Wild Turkey ${ }^{\circledR}$ ) or 100 proof vodka $\left(\right.$ Absolut $\left.{ }^{\circledR}\right)$, mixed with chilled caffeine-free cola $\left(\right.$ Coke $\left.^{\circledR}\right)$. The placebo for both these beverages was caffeine-free cola plus de-carbonated tonic, in amounts equivalent to the alcoholic beverage, chilled, with a few drops of vodka or bourbon floated on top. 
Beverages were served in plastic cups between 8.45 p.m. and 10.00 p.m. in studies 2 and 3 and between 7.30 and 9.00 p.m. in study 1 , in small groups of three to five participants. (Dosing times varied according to the availability of facilities at the study sites.)

Total beverage volume was determined by dosing tables with the number of milliliters of alcohol by weight and gender, and in the case of bourbon and vodka, the number of milliliters of caffeine-free cola (with a ratio of one part vodka or bourbon to four parts cola).

Participants were told the number of cups of beverage they were to consume in an hour and to pace their drinking. In studies 1 and 2, each cup was equivalent to one bottle of beer and participants were asked to complete their dose before being breath-tested. In study 3, the total amount of beverage was divided into three equal portions. Participants were breath-tested 15 minutes after completing two of the three portions. Depending on their BrAC relative to the target, they then received an adjusted final quantity of beverage. Unfinished beverage was measured so that the exact amount of beverage consumed by each participant could be documented. To maintain double-blinding, the research staff who prepared beverages and conducted breath tests were different from those who collected all other measures.

After drinking and a 30-minute absorption period, participants completed subjective measures, received snacks and were escorted to individual rooms for an 8-hour sleep period, observed by nursing students (study 1) or a licensed emergency medical technician (studies 2 and 3).

Participants were awakened at 7.00 a.m. They completed the hangover rating scale, ate breakfast and were breath-tested. At 8.00 a.m. they completed other questionnaires and performance measures (these times were 1 hour earlier for study 1). The time of day was based on literature indicating that subjective effects of hangover are most detectable before 10.00 a.m. [44] and that decrements in performance the day after heavy drinking were limited to the morning [20]. Performance during the first 30 minutes after waking is likely to be impaired by sleep inertia [45]; allowing an hour before performance testing avoids this potential confounder.

\section{Assessments}

Hangover was assessed using the nine-item validated Acute Hangover Scale [38]. Participants rated 'hangover' on a scale ranging from 0 (none) to 7 (incapacitating) and eight symptoms (thirst, tiredness, headache, dizziness or faintness, nausea, stomach ache, heart racing and loss of appetite), selected from previous studies $[3,44,46]$. In the data analyses for this study, the 'hangover' and the discrete symptoms were coded as present or absent (positive rating versus zero). Hangover severity was coded as follows: $0=$ none; $1-2=$ mild; $3-5=$ moderate; and $6-7=$ severe.

Participants' gender and age were recorded at enrollment. The interviewer-administered Family Tree Questionnaire [47] determined FHx, with a first- or second-degree relative with alcohol problems coded as FHx positive. ADV of alcohol intake was calculated to establish recent drinking practices (other than when participating in the study) using a two-item alcohol use questionnaire: (i) 'Considering all your drinking times in the past 30 days, about how often did you have any beer, wine or liquor?', rated from 1 'once a day' to 7 'did not drink' with each point anchored; and (ii) 'In the past 30 days, on a typical day that you drank, about how much did you have to drink in one day?', rated from 1 to 8 , with choices of one to seven drinks and 'eight or more drinks'. One drink was defined as $12 \mathrm{oz}$ of beer or wine cooler, $4 \mathrm{oz}$ of wine or $1 \mathrm{oz}$ of liquor.

\section{Data analyses}

We used $\chi^{2}$ analysis to assess participant differences by type of alcoholic beverage received and differences in specific hangover symptoms. We used a logistic regression model with incidence of hangover ( 0 versus $\geq 1$ on the hangover question scale) as the dependent variable and gender, age, type of alcoholic beverage received, FHx and ADV as independent variables. Adjusted odds ratios and 95\% confidence intervals from this model are reported.

\section{Human subjects}

The studies in these analyses were approved by the Institutional Review Boards at Boston University Medical Center and Brown University (studies 1-3) and the University of Michigan (study 3).

\section{RESULTS}

\section{Frequency and severity of hangover}

In the placebo condition, 97\% (167) reported no hangover and 3\% (five) reported mild hangover. In the alcohol condition, $24.4 \%$ (42) of participants reported no hangover; $43.6 \%$ (75) reported mild hangover; and 31.9\% (55) reported moderate hangover. None reported severe hangover. Incidences of all symptoms were significantly greater for those reporting greater hangover severity levels. Frequency of each symptom by hangover severity level is displayed in Table 2.

\section{Hangover by characteristics of participants and beverage type}

In multivariate analysis, none of the independent variables was a significant predictor of hangover. The beta 
Table 2 Frequency of hangover symptoms by hangover severity.

\begin{tabular}{|c|c|c|c|c|}
\hline \multirow[b]{2}{*}{$\begin{array}{l}\text { Symptoms associated } \\
\text { with hangover }\end{array}$} & \multicolumn{4}{|c|}{ Hangover severity } \\
\hline & $\begin{array}{l}\text { No hangover } \\
(n=42)\end{array}$ & $\begin{array}{l}\text { Mild } \\
(n=75)\end{array}$ & $\begin{array}{l}\text { Moderate } \\
(n=55)\end{array}$ & $\begin{array}{l}\chi^{2} \\
(2 d f)\end{array}$ \\
\hline Thirst & $38(90.5 \%)$ & $75(100 \%)$ & $55(100 \%)$ & $12.68^{*}$ \\
\hline Tiredness & $36(85.7 \%)$ & $72(97.3 \%)$ & $55(100 \%)$ & $12.14^{*}$ \\
\hline Headache & $6(14.3 \%)$ & $43(57.3 \%)$ & $43(78.2 \%)$ & $39.87^{* *}$ \\
\hline Dizziness/faintness & $3(7.1 \%)$ & $28(37.3 \%)$ & $37(67.3 \%)$ & $36.29^{* *}$ \\
\hline Loss of appetite & $10(23.8 \%)$ & $28(37.3 \%)$ & $30(54.6 \%)$ & $9.68^{*}$ \\
\hline Stomach ache & $3(7.1 \%)$ & $12(16.0 \%)$ & $22(40.0 \%)$ & $17.62^{* *}$ \\
\hline Nausea & $1(2.4 \%)$ & $12(16.0 \%)$ & $21(38.2 \%)$ & $20.43^{* *}$ \\
\hline Heart racing & $1(2.4 \%)$ & $8(10.7 \%)$ & $15(27.3 \%)$ & $13.49^{*}$ \\
\hline
\end{tabular}

${ }^{*} P<0.01 ; * * P<0.001$

Table 3 Multivariate analysis of hangover under alcohol condition.

\begin{tabular}{|c|c|c|}
\hline Predictor variables & Odds ratio & $\begin{array}{l}95 \% \text { confidence } \\
\text { interval }\end{array}$ \\
\hline \multicolumn{3}{|l|}{ Sex } \\
\hline Male & 1.63 & $0.68,3.91$ \\
\hline Female & Referent & \\
\hline \multicolumn{3}{|l|}{ Age } \\
\hline $21-25$ & 1.10 & $0.24,5.05$ \\
\hline $26-40$ & 1.21 & $0.27,5.47$ \\
\hline$>40$ & Referent & \\
\hline \multicolumn{3}{|l|}{ FHx for drinking problems } \\
\hline Positive & 0.91 & $0.41,2.03$ \\
\hline Negative & Referent & \\
\hline $\begin{array}{l}\text { Decrease in average daily } \\
\text { volume }\end{array}$ & 0.78 & $0.54,1.11$ \\
\hline \multicolumn{3}{|l|}{ Beverage type } \\
\hline Beer & 0.85 & $0.34,2.14$ \\
\hline Bourbon & 1.41 & $0.47,4.20$ \\
\hline Vodka & Referent & \\
\hline
\end{tabular}

Logistic regression model simultaneously adjusts for all predictors. All differences were non-significant. C-statistic $=0.59$; FHx: family history.

sign for ADV was negative (i.e. as ADV increases, the odds of hangover increase). The C-statistic for the logistic regression model was 0.59 (Table 3).

\section{DISCUSSION}

The morning after a mean peak $\mathrm{BrAC}$ of $0.11 \mathrm{~g} \%, 24 \%$ of these healthy drinkers reported no hangover. Although most survey data do not control for the level of alcohol consumption and tend to use some unit of time (e.g. prior year) in the incidence measure, our results are consistent with those of Harburg et al. [6], who found that $23 \%$ of a sample of drinkers reported not having had a hangover the last time they were intoxicated and those of Pristach et al. [7], who found that $23 \%$ of a sample of alcoholics reported never having had a hangover. Our findings were also comparable to the one experimental study that reported the incidence of hangover after intoxication [3]. Chapman found that $29 \%$ of participants with $\mathrm{BrAC}$ levels (mean $\mathrm{BrAC}=0.124 \mathrm{~g} \%$; range $=0.10-0.15 \mathrm{~g} \%$ ), comparable to our participants' BrAC levels, reported no hangover the morning after alcohol administration, using the same scale metric as used in our study [3]. The consistency indicates that the incidence and severity levels we obtained are reliable for this level of intoxication.

In our study, congener differences between beverages did not account for differences in hangover severity. As $28 \%$ of our vodka drinkers reported moderate hangover, our result is not consistent with Chapman's [3] finding that bourbon yielded more moderate hangover $(33 \%$ of participants) than did vodka (3\%). Moreover, our findings are inconsistent with those of Pawan [29], who found that severity of hangover increased with congener content of alcoholic beverages. These inconsistencies might be attributable to differences in hangover measurement.

In logistic regression, the other characteristics we investigated as predictors of hangover were all nonsignificant. The lack of difference in hangover incidence by gender is consistent with some other studies [3,6,37], but not all. Verster et al. [48] found that hangover severity score differed by gender the day after alcohol administration. The gender difference reported by Smith \& Barnes [27] did not include significance tests and could have been confounded by differences in drinking practices. In our study, age was not associated significantly with hangover incidence, although the range of ages in was limited (21-57 years, with $80 \%$ under 30 years of age). Other studies have not reported on the relationship between age and hangover propensity.

Our finding of no relationship between self-reported daily drinking quantity and hangover incidence was 
inconsistent with most of the survey literature, but we might not have been able to test this hypothesis given the restrictions of range due to the fact that all our participants were heavy episodic drinkers. Alternatively, the survey studies reviewed might have found a relationship, because people who rarely drink heavily rarely have any opportunity to experience hangover. However, we ensured that all participants experienced a hangover opportunity.

Our findings of no association between hangover and FHx contrasts with those of several other investigators [30-34], but are consistent with the findings of Earleywine [35] and Richardson [36]. However, only one of these previous studies involved experimental administration of alcohol [32], and interestingly, that study found that FHx positive participants reported higher incidence of 'hangover' following both alcohol and placebo administration.

FHx, however, is a complex construct that potentially includes both genetic and environmental components. While it is not possible to disentangle these components in studies comparing people only by $\mathrm{FHx}$, genetic factors per se might be an avenue for further exploration. In a study of white college students, Wall et al. [49] found that individuals with an alcohol dehydrogenase gene polymorphism (ADH 1 B*2 allele) reported more severe hangovers than those lacking this allele.

Our study adds information about the incidence of symptoms associated commonly with hangover. All the symptoms were those validated in previous experimental hangover studies and the set of symptoms form a highly reliable scale across several data sets [38]. While most of the symptoms were reported far less frequently by those reporting no hangover than by those with mild or severe hangover, thirst and tiredness were reported by 85-90\% of those who reported no hangover. This could indicate that these individuals were experiencing residual effects of alcohol but not attributing them to the drinking the night before, or that people commonly wake up tired and thirsty. Because the severity of these two symptoms differed between alcohol and placebo days at $P<0.0001$ [38] they are likely to be valid symptoms, but it may be that most people experience these the morning after drinking to intoxication whether or not they attribute the cause to hangover.

Several limitations of our study warrant comment. For participant safety, our target BrAC was moderate [about two-thirds the average BAC in US driving under the influence (DUI) arrests] and more participants might have reported hangover had they received more alcohol. Blinding participants to dosing status is difficult when targeting intoxication. Under the alcohol condition, of those who thought they had received alcohol 79.97\% reported hangover, and of those who thought they had received placebo 20\% reported hangover (data not shown). Other limitations of our study include having only one targeted BrAC level, having no measure of acquired tolerance to alcohol, and not having more putative predictors of hangover. Use of tobacco might be another factor affecting propensity for hangover. We could not examine the smoking/hangover relationship because complete data on nicotine exposure (e.g. chewing tobacco, popular in Sweden) were not collected on study 1 participants and because smokers were excluded in studies 2 and 3. Despite these limitations, this study is one of few to report incidence of hangover after a controlled level of intoxication and thus it adds to a limited literature.

In summary, the lack of significant individual difference predictors despite observed variation in hangover intensity demonstrates the need for further research to determine individual differences that account for differing levels of hangover severity after about the same peak BrAC level. Our findings on the propensity for hangover, the findings from the previous experimental study [3], and those from surveys of drinkers [6,7], suggest that $25-30 \%$ of drinkers may be resistant to hangover.

\section{Acknowledgements}

This research was supported by: (i) the Harvard Injury Control Research Center, with funding from the Centers for Disease Control and Prevention grant R49CCR115279; (ii) the National Institute on Alcohol Abuse and Alcoholism (NIAAA) grant no. R01 AA12087 to the Boston University School of Public Health; (iii) by the National Center for Research Resources, General Clinical Research Center grant M01 RR00533; and (iv) the Youth Alcohol Prevention Center, Boston University School of Public Health, with funding from NIAAA grant no. P60 AA013759-01. We thank Erika Edwards MPH, Project Manager at the Data Coordinating Center at the Boston University School of Public Health for her assistance in analyzing NESARC data.

\section{References}

1. Wiese J. G., Shlipak M. G., Browner W. S. The alcohol hangover. Ann Intern Med 2000; 132: 897-902.

2. Swift R., Davidson D. Alcohol hangover. Alcohol Health Res World 1998; 22: 54-60.

3. Chapman L. Experimental induction of hangover. Q J Stud Alcohol 1970; 5: 67-86.

4. Frone M. R. Prevalence and distribution of alcohol use and impairment in the workplace: a U.S. national survey. J Stud Alcohol 2006; 67: 147-56.

5. Meilman P. W., Stone J. E., Gaylor M. S., Turco J. H. Alcohol consumption by college undergraduates: current use and 10-year trends. J Stud Alcohol 1990; 51: 389-95.

6. Harburg E., Gunn R., Gleiberman L., DiFranceisco W., 
Schork A. Psychosocial factors, alcohol use, and hangover signs among social drinkers: a reappraisal. J Clin Epidemiol 1993; 45: 413-22.

7. Pristach C. A., Smith C. M., Whitney R. B. Alcohol withdrawal symptoms: prediction from detailed medical and drinking histories. Drug Alcohol Depend 1983; 11: 177-99.

8. Finnigan F., Hammersley R., Cooper T. An examination of next-day hangover effects after a $100 \mathrm{mg} / 100 \mathrm{ml}$ dose of alcohol in heavy social drinkers. Addiction 1998; 93: 182938.

9. Chait L. D., Perry J. L. Acute and residual effects of alcohol and marijuana, alone and in combination, on mood and performance. Psychopharmacology 1994; 115: 340-9.

10. Lemon J., Chesher G., Fox A., Greeley J., Nabke C. Investigation of the 'hangover' effects of an acute dose of alcohol on psychomotor performance. Alcohol Clin Exp Res 1993; 17: 665-8.

11. Takala M., Siro E., Toivainen Y. Intellectual functions and dexterity during hangover: experiments after intoxication with brandy and with beer. Q J Stud Alcohol 1958; 19: 1-29.

12. Rohsenow D. J., Howland J., Minsky S. J., Arnedt J. T. Effects of heavy drinking by maritime academy cadets on hangover, perceived sleep, and next-day ship power plant operation. J Stud Alcohol 2006; 67: 406-15.

13. Streufert S., Pogash R., Braig D., Gingrich D., Kantner A., Landis R. et al. Alcohol hangover and managerial effectiveness. Alcohol Clin Exp Res 1995; 19: 1141-6.

14. Yesavage J., Dolhert N., Taylor J. Flight simulator performance of younger and older aircraft pilots: effects of age and alcohol. J Am Geriatr Soc 1994; 42: 577-82.

15. Morrow D., Leirer V., Yesavage J. The influence of alcohol and aging on radio communication during flight. Aviat Space Environ Med 1990; 61: 12-20.

16. Morrow D., Leirer V., Yesavage J., Tinklenberg J. Alcohol, age, and piloting: judgment, mood, and actual performance. Int J Addict 1991; 26: 669-83.

17. Morrow D., Yesavage J., Leirer V., Dohlert N., Taylor J., Tinkleberg J. The time-course of alcohol impairment of general aviation pilot performance in a Frasca 141 Simulator. Aviat Space Environ Med 1993; 64: 697-705.

18. Taylor J., Dohlert N., Morrow D., Friedman L., Yesavage J. Acute and 8-hangover effects of alcohol $(0.08 \%$ BAC) in younger and older pilots' simulator performance. Aviat Space Environ Med 1994; 65: 718-25.

19. Taylor J. L., Dolhert N., Friedman L., Mumenthaler M., Yesavage J. A. Alcohol elimination and simulator performance of male and female aviators: a preliminary report. Aviat Space Environ Med 1996; 67: 407-13.

20. Tornros J., Laurell H. Acute and hang-over effects of alcohol on simulated driving performance. Blutalkohol 1991; 28: 24-30.

21. Yesavage J., Leirer V. Hangover effects on aircraft pilots 14 hours after alcohol ingestion: a preliminary report. Am J Psychiatry 1986; 143: 1546-50.

22. Collins W. Performance effects of alcohol intoxication and hangover at ground level and at simulated altitude. Aviat Space Environ Med 1980; 51: 327-35.

23. Collins W., Chiles W. Laboratory performance during acute alcohol intoxication and hangover. Hum Factors 1980; 22: 445-62.

24. Wolkenberg R., Gold C., Tichauer E. Delayed effects of acute alcohol intoxication on performance with reference to work safety. J Saf Res 1975; 7: 104-19.

25. Nathan P. E., Zare N. C., Ferneau E. W. Jr, Lowenstein L. M.
Effects of congener differences in alcoholic beverages on the behavior of alcoholics. Q J Stud Alcohol 1970; Suppl. 5: $87-100$.

26. Katkin E. S., Hayes W. N., Teger A. I., Pruitt D. G. Effects of alcoholic beverages differing on congener content on psychomotor tasks and risk taking. Q J Stud Alcohol 1970; Suppl. 5: 101-14.

27. Smith C. M., Barnes G. M. Signs and symptoms of hangover: prevalence and relationship to alcohol use in a general adult population. Drug Alcohol Depend 1983; 11: 249-69.

28. Greizerstein H. B. Congener contents of alcoholic beverages. J Stud Alcohol 1981; 42: 1030-7.

29. Pawan G. L. S. Alcoholic drinks and hangover effects. Proc Nutr Soc 1973; 32: 15A.

30. Newlin D. B., Pretorius M. B. Sons of alcoholics report greater hangover symptoms than sons of nonalcoholics: a pilot study. Alcohol Clin Exp Res 1990; 14: 713-16.

31. McCaul M. E., Turkkan J. S., Svikis D. S., Bigalow G. E. Alcohol and serobarbital effects as a function of familial alcoholism: extended intoxication and increased withdrawal effects. Alcohol Clin Exp Res 1991; 15: 94-101.

32. Span S. A., Earleywine M. Familial risk for alcoholism and hangover symptoms. Addict Behav 1999; 24: 121-5.

33. Slutske W. S., Piasecki T. M., Hunt-Carter E. E. Development and initial validation of the Hangover Symptom Scale: prevalence and correlates of hangover symptoms in college students. Alcohol Clin Exp Res 2003; 27: 1442-50.

34. Piasecki T. M., Sher K. J., Slutske W. S., Jackson K. M. Hangover frequency and risk for alcohol use disorders: evidence from a longitudinal high-risk study. J Abnorm Psychol 2005; 114: 223-34.

35. Earleywine M. Personality risk for alcoholism covaries with hangover symptoms. Addict Behav 1993; 18: 415-20.

36. Richardson A. E. Exploring the relation between cigarette smoking and alcohol hangover frequency. Unpublished Master's thesis, University of Missouri, Columbia, Missouri, May 2007 .

37. Kauhanen J., Kaplan G. A., Goldberg D. D., Cohen R. D., Lakka T. A., Salonen J. T. Frequent hangovers and cardiovascular mortality in middle-aged men. Epidemiology 1997 2007; 8: 310-14.

38. Rohsenow J. D., Howland J., Minsky S., Greece J., Almeida A., Roehrs T. A. The Acute Hangover Scale: a new measure immediate hangover symptoms. Addict Behav 2007; 32: 1314-20.

39. Selzer M. D., Vinokur A., Van Rooijen L. A self-administered Short Michigan Alcohol Screening Test (SMAST). J Alcohol 1975; 36: 117-26.

40. Brick J., Nathan P. E., Westrick E., Frankenstein W., Shapiro A. The effects of menstrual cycle on blood alcohol levels and behavior. J Stud Alcohol 1986; 47: 472-7.

41. Niaura R. S., Nathan P. E., Frankenstein W., Shapiro A. P., Brick J. Gender differences in acute psychomotor, cognitive, and pharmacokinetic response to alcohol. Addict Behav 1987; 12: 345-56.

42. Terner J. M., deWit H. Menstrual cycle phase and responses to drugs of abuse in humans. Drug Alcohol Depend 2006; 84: $1-13$.

43. Friel P. N., Logan B. K., O'Malley D., Baer J. S. Development of dosing guidelines for reaching selected target breath alcohol concentrations. J Stud Alcohol 1999; 60: 555-65.

44. Ylikahri R., Huttumen M., Eriksson C. J. P., Hikkila E. A. Metabolic studies on the pathogenesis of hangover. Eur J Clin Invest 1974; 4: 93-100. 
45. Tassi P., Muzet A. Sleep inertia. Sleep Med Rev 2000; 4: 341-53.

46. Roehrs T., Yoon J., Roth T. Nocturnal and next-day effects of ethanol and basal level of sleepiness. Hum Psychopharmacol 1991; 6: 307-11.

47. Mann R. E., Sobell L. C., Sobell M. B., Pavan D. Reliability of a family tree questionnaire for assessing FHx of alcohol problems. Drug Alcohol Depend 1985; 15: 61-7.
48. Verster J. C., van Duin D., Volkerts E. R., Schreuder A., Verbaten M. N. Alcohol hangover effects on memory functioning and vigilance performance after an evening of binge drinking. Neuropsychopharmacology 2003; 28: 740-6.

49. Wall T. L., Luczak S. E., Carr L. G., Shea S. H., Cook T. A. R. Genetic associations of alcohol dehydrogenase with alcohol use disorders and endophenotypes in white college students. J Abnorm Psychol 2005; 114: 456-65. 